Acknowledgment. We wish to express our thanks to Dr. A. Ueno, Mr. T. Kondo, Mr. K. Sasaki, Mr. T. Sato, and Mrs. H. Ando of the Instrumental Analysis Center for Chemistry, Tohoku University, for the measurements of ${ }^{1} \mathrm{H}$ and ${ }^{13} \mathrm{C}$ NMR spectra, mass spectra, and microanalyses. We also would like to thank Dr. H. Hagiwara of the Chemical Research Institute of Non-Aqueous solution, Tohoku University, for the measurements of high-resolution mass spectra.

Rezistry No. 1, 66767-50-8; 2, 110193-06-1; 3, 135645-75-9; $4,135645-76-0 ; 5,135645-77-1 ; 6,135645-78-2 ; 7,135645-79-3 ; 8$, 135645-80-6; 9, 135645-81-7; 10, 135645-82-8; 11, 135645-83-9; 12, $135645-84-0 ; 13,29642-62-4$.

\section{Methanesulfonate/p-Nitrobenzoate and $p$-Toluenesulfonate/p-Nitrobenzoate Rate Ratios. Solvolyses of 1-Adamantyl and Benzhydryl Substrates}

T. William Bentley, Manfred Christl, and Simon J. Norman

\section{Department of Chemistry, University College of Swansea, Singleton Park, Swansea SA2 8PP, Wales, U.K., and} Institut für Organische Chemie, Universitat Würzburg, Am Hubland, Würzburg, D-8700, Germany

Received May 8, 1991

Alcohols derivatized as benzoate or sulfonate esters are frequently employed as precursors of carbocationic species generated in solvolytic reactions. ${ }^{2}$ Typically, reactivities of a series of compounds having the same leaving group are examined in individual projects. Comparisons of substituent effects on kinetic data for different benzoates OR sulfonates can readily be made, ${ }^{2}$ but comparisons of benzoates AND sulfonates (i.e., $p$-nitrobenzoates and tosylates) are difficult because benzoates are about $10^{8}$-fold less reactive than sulfonates. ${ }^{3}$

Improved methods for determining first-order solvolysis rate constants have extended the conveniently accessible range to fast reactions having half-lives of $\langle 1 \mathrm{~s}$, 4 and sulfonates too unstable to be isolated at room temperature have recently been studied. ${ }^{6}$ Also, kinetics of reactions of sparingly soluble substrates can now be examined conveniently by HPLC monitoring of the disappearance of the substrate; as the "infinity" value (equal to zero substrate concentration) can be assumed, this method is well-suited to very slow reactions. ${ }^{7,8}$ A combination of these two

(1) Streitwieser, A., Jr. Chem. Rev. 1956, 56, 671.

(2) (a) Kevill, D. N.; Kolwyck, K. C.; Weitl, F. L. J. Am. Chem. Soc. 1970, 92, 7300. (b) Kevill, D. N.; Kolwyck, K. C.; Shold, D. M.; Kim, C. J. Am. Chem. Soc. 1973, 95, 6022. (c) Liu, K.-T.; Lee. J.-K.; Chen, H. I. J. Org. Chem. 1990, 55, 3662.

(3) (a) Allen, A. D.; Kanagasabapathy, V. M.; Tidwell, T. T. J. Am Chem. Soc. 1886, 108, 3470. (b) Noyce, D. S.; Virgilio, J. A. J. Org. Chem 1972, 37, 2643.

(4) (a) Parker, W.; Tranter, R. L.; Watt, C. I. F. Chang, L. W. K Schleyer, P. v. R. J. Am. Chem. Soc. 1974, 96, 7121. (b) Bentley, T. W Bowen, C. T.; Parker, W. Watt, C. I. F.J. Chem. Soc., Perkin Tran 2 1980, 1244. (c) Bentley, T. W. Carter, G. E. J. Org. Chem. 1983, 48, $21980,1244$. (c) Bentley, T. W.; Carter, G. E. J. Org. Chem. 1983, 48,
579. (d) Bentley, T. W.; Harris, H. C.; Koo, I. S. J. Chem. Soc., Perkin Trans. 2 1988, 783. (e) Takeuchi, K.; Ikai, K.; Shibata, T.; Trugeno, A J. Org. Chem. 1988, 53, 2852.

(5) (a) Perlmutter-Hayman, B.; Wolff, M. A. Isr. J. Chem. 1965, 3, 155. (b) Nordlander, J. E.; Gruetzmacher, R. R.; Kelly, W. J.; Jindal, S. P. J. Am. Chem. Soc. 1974, 96, 181. (c) Hill, S. V.; Thea, S.; Williams. A. J. Chem. Soc., Perkin Trans. 2 1983, 437. (d) McGarrity, J. F.; Prodolliet, J. J. Org. Chem. 1984, 49, 4465.

(6) Bentley, T. W.; Kirmse, W.; Llewellyn, G.; Sollenbohmer, F. J. Org. Chem. 1990, 55, 1536.
Table I. Rate Constants (k) for Solvolyses of Benzhydryl Mesylate (1, X = OMs)e

\begin{tabular}{cclc}
\hline solvent & temp, $^{\circ} \mathrm{C}$ & \multicolumn{1}{c}{$k, \mathrm{~s}^{-1}$} & $Y_{\mathrm{OM}^{b}}$ \\
\hline $80 \%$ EtOH $^{d}$ & -17.1 & $(1.64 \pm 0.02) \times 10^{-1}$ & \\
& -9.6 & $(4.18 \pm 0.05) \times 10^{-1}$ & 0.0 \\
& 0.8 & $1.31 \pm 0.01$ & \\
& 25.0 & 14.8 & \\
$90 \%$ EtOH $^{d}$ & -9.2 & $(1.34 \pm 0.01) \times 10^{-1}$ & -0.82 \\
EtOH & -9.2 & $(1.22 \pm 0.05) \times 10^{-2}$ & -2.22
\end{tabular}

- Determined conductimetrically at least in duplicate; errors shown are average deviations. ${ }^{b}$ Values at $25^{\circ} \mathrm{C}$ from ref $9 \mathrm{~b}$; an $m$ value of $0.78 \pm 0.06$ is obtained for solvolyses of 1 at $-9{ }^{\circ} \mathrm{C}$ ' Calculated from rate constants at lower temperatures; $\Delta H^{*}=15.5$ $\mathrm{kcal} \mathrm{mol}{ }^{-1}, \Delta S^{*}=-0.9 \mathrm{cal} \mathrm{mol}^{-1} \mathrm{~K}^{-1}$. $8 \% \mathrm{v} / \mathrm{v}$ ethanol $/$ water.

Table II. Rate Constants ( $k$ ) for Solvolyses of Benzhydryl $p$-Nitrobenzoate $\left(1, \mathrm{X}=\mathrm{OCOC}_{6} \mathrm{H}_{6} \mathrm{NO}_{3}\right)$ in $80 \%$ Ethanol/Water

\begin{tabular}{clcc}
\hline temp, ${ }^{\circ} \mathrm{C}$ & \multicolumn{1}{c}{$k, \mathrm{~s}^{-1}$} & $\begin{array}{c}\Delta H^{\dagger}, \\
\mathrm{kcal} / \mathrm{mol}\end{array}$ & $\begin{array}{c}\Delta \mathrm{S}^{*}, \mathrm{cal} \\
\mathrm{mol}^{-1} \mathrm{~K}^{-1}\end{array}$ \\
\hline $100.0^{\circ}$ & $3.48 \times 10^{-6}$ & & \\
$100.3^{b}$ & $(3.34 \pm 0.05) \times 10^{-6}$ & & \\
$75.2^{b}$ & $(2.70 \pm 0.01) \times 10^{-6}$ & 25.6 & -11.0 \\
$59.5^{b}$ & $(4.33 \pm 0.13) \times 10^{-7}$ & & \\
$25.0^{c}$ & $4.5 \times 10^{-8}$ & &
\end{tabular}

- Determined spectrophotometrically from the rate of appearance of acid. ${ }^{10}$ Determined in duplicate by HPLC from the rate of disappearance of ester in buffered solution; the rate of appear. ance of acid gave slightly higher results having greater uncertainty. c Calculated from rate constants at higher temperatures.

Table III. Rate Constants ( $k$ ) for Solvolyses of 1-Adamantyl Esters (2) in 60\% v/v Ethanol/Water

\begin{tabular}{crlcc}
\hline $\begin{array}{c}\text { leaving } \\
\text { group (X) }\end{array}$ & $\begin{array}{c}\text { temp, } \\
{ }^{\circ} \mathrm{C}\end{array}$ & \multicolumn{1}{c}{$k, \mathrm{~s}^{-1}$} & $\begin{array}{c}\Delta H^{*}, \\
\mathrm{kcal} / \mathrm{mol}\end{array}$ & $\begin{array}{c}\Delta \mathrm{S}^{*}, \\
\mathrm{cal} \mathrm{mol} \mathrm{H}^{-1} \mathrm{~K}^{-1}\end{array}$ \\
\hline $\mathrm{OMg}^{a}$ & 25.0 & $(5.16 \pm 0.04) \times 10^{-2}$ & $17.8^{b}$ & $-4.7^{b}$ \\
$\mathrm{OMs}^{\circ}$ & 35.0 & $(1.41 \pm 0.03) \times 10^{-1}$ & 17.9 & -4.4 \\
$\mathrm{OMg}^{a}$ & 50.0 & $(5.77 \pm 0.12) \times 10^{-1}$ & & \\
$\mathrm{OMg}^{c}$ & 75.0 & 4.6 & & \\
PNB $^{d}$ & 129.2 & $(7.76 \pm 0.2) \times 10^{-6}$ & & \\
PNB $^{d}$ & 101.7 & $(5.16 \pm 0.1) \times 10^{-7}$ & 28.8 & -11.0 \\
PNB $^{c}$ & 75.0 & $2.5 \times 10^{-8}$ & &
\end{tabular}

- Mesylate (OMs) determined conductimetrically at least in duplicate; errors shown are average deviations. 'b Reference 4c. calculated from rate constants at other temperatures. 'p-Nitrobenzoate (PNB) determined by HPLC from the rate of disappearance of ester in buffered solution-the rate of appearance of acid gave similar but less precise results; an additional rate constant of $(3.18 \pm 0.03) \times 10^{-6}$ was obtained for $40 \%$ ethanol/water at 101.5 ${ }^{\circ} \mathrm{C}$.

methods allows reliable, direct measurements of first-order rate constants spanning at least seven orders of magnitude.

We now report rate constants for solvolyses of benzhydryl (1) and 1-adamantyl (2) p-nitrobenzoates and methanesulfonates (mesylates) in aqueous ethanol, providing the first reliable measurements of sulfonate $/ p$ nitrobenzoate rate ratios. When combined with the known trends in substituent effects ${ }^{2}$ and solvent effects (from the Grunwald-Winstein treatment ${ }^{9}$ ), these new data link an unusually diverse range of published kinetic data.

\section{Results}

The fast-response conductimetric method 4 was applied to solvolyses of benzhydryl mesylate $(1, \mathrm{X}=0 \mathrm{Ms})$ in pure

(7) (a) Merzelsbers, I.: Ruchardt, C. Tetrahedron Lett. 1982, 23, 1809. (b) Slutsky, J.; Bingham, R. C.; Schleyer, P. v. R; Dickason, W. C.; Brown, H. C. J. Am. Chem. Soc. 1974, 96, 1969

(8) Bentley, T. W., Gream, G. E. J. Org. Chem. 1985, 50, 1776.

(9) (a) Grunwald, E.; Winstein, S. J. Am. Chem. Soc. 1948, 70, 846. (b) Bentley, T. W.; Llewellyn, G. Prog. Phys. Org. Chem. 1990, 17, 121 


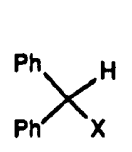

1

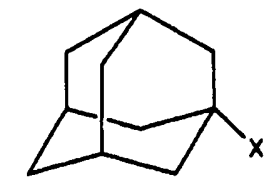

$\left(\mathrm{CH}_{3}\right)_{3} \mathrm{CX}$

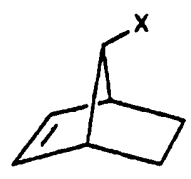

4

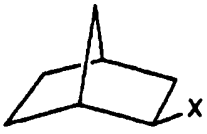

ethanol and in 90 and $80 \%$ aqueous ethanol (Table I) and to solvolyses of 1-adamantyl mesylate $(2, \mathrm{X}=\mathrm{OMs})$ in $60 \%$ aqueous ethanol (Table III). Corresponding solvolyses of $p$-nitrobenzoates $\left(1,2, \mathrm{X}=\mathrm{OCOC}_{6} \mathrm{H}_{4} \mathrm{NO}_{2}\right)$, investigated by HPLC, are shown in Tables II and III; these have been studied previously at high temperatures, ${ }^{7,10}$ and the required alkyl-oxygen cleavage has been shown to be dominant by the incorporation of ${ }^{18} \mathrm{OH}_{2}$ from $70 \%$ acetonitrile/water into the 1-adamantanol $(2, \mathrm{X}=\mathrm{OH})$ formed during solvolyses of $2\left(\mathrm{X}=\mathrm{OCOC}_{6} \mathrm{H}_{4} \mathrm{NO}_{2}\right)$ at 150 ${ }^{\circ} \mathrm{C}$. ${ }^{7 a}$ Also, in our work, ethyl $p$-nitrobenzoate (a product of acyl-oxygen fission in ethanol/water mixtures) was observed in only trace amounts (about $1 \%$ ) and was stable under the reaction conditions. Reactions were buffered with 2,6-dimethylpyridine to avoid acid catalysis and to minimize buffer catalysis. ${ }^{11}$

Temperature extrapolations of only $25-35^{\circ} \mathrm{C}$ were required to obtain the mesylate/p-nitrobenzoate rate ratios for solvolyses of 1 and 2 (Table IV). Tosylate/mesylate rate ratios, which are slightly solvent dependent but are close to unity, ${ }^{9 b}$ were then used to calculate tosylate $/ p$ nitrobenzoate rate ratios (Table IV).

Benzhydryl tosylate $1\left(\mathrm{X}=0 \mathrm{OT}_{\mathrm{s}}\right)$ has previously been isolated, and the preliminary rate constant of $4.5 \times 10^{-3}$ $\mathrm{s}^{-1}$ in $90 \% \mathrm{THF} /$ water at $0^{\circ} \mathrm{C}^{13}$ is $2-4$-fold slower than we estimate from our results; tosylates are less suitable for fast kinetics because they dissolve much less rapidly than mesylates.

\section{Discussion}

Previous estimates of tosylate/ $p$-nitrobenzoate rate ratios, varying nearly 3 orders of magnitude from $9.4 \times 10^{6}$ to $6.7 \times 10^{9},{ }^{3}$ have usually involved long temperature extrapolations and other assumptions linking data from three or four different sources. Our tosylate/p-nitrobenzoate rate ratios (Table IV) are toward the high end of the published range, significantly higher than the "rounded" value of $10^{8}$ chosen recently. Three additional, directly determined, values are also given in Table IV.

Previous estimates of tosylate/ $p$-nitrobenzoate rate ratios ${ }^{3}$ and the literature values for substrates 3-5 (Table IV) required longer temperature extrapolations than those

(10) McLennan, D. J.; Martin, P. L. Aust. J. Chem. 1979, 32, 2361. (11) Kantner, S. S.; Humski, K.; Goering, H. L. J. Am. Chem. Soc. 1982, 104, 1693 .

(12) (a) Brown, H. C.; Dickason, W. C. J. Am. Chem. Soc. 1969, 91 , 1226. (b) Gasaman P. G. Patton D'S J Am Chem Soc 1969 91 2160' (c) Battinte, M. A.; Deyrup, C. L.; Pincock, R. E.; Haywood-Farmer, J. J. Am. Chem. Soc. 1967, 89, 1954. (d) Winstoin, S.; Shatavsky, M.; Norton, C.; Woodward, R. B. J. Am. Chem. Soc. 1955, 77, 4183. (e) Harris, J. M.; Mount, D. L.; Raber, D. J. J. Am. Chem. Soc. 1978, 100, 3139.

(13) Ledwith, A.; Morris, D. G. J. Chem. Soc. 1964, 308.
Table IV. Sulfonate/p-Nitrobenzoate Rate Ratios

\begin{tabular}{ccccc}
\hline & & & \multicolumn{2}{c}{ rate ratio } \\
\cline { 4 - 5 } substrate & 8olvent & temp, ${ }^{\circ} \mathrm{C}$ & $\begin{array}{c}\text { OMs/ } \\
\text { OPNB }\end{array}$ & $\begin{array}{c}\text { OTs } / \\
\text { OPNB }\end{array}$ \\
\hline $1^{b}$ & $80 \%$ EtOH & 25.0 & $3.3 \times 10^{\circ}$ & $3.3 \times 10^{9}$ \\
$2^{c}$ & $60 \%$ EtOH & 75.0 & $1.9 \times 10^{8}$ & $1.7 \times 10^{\circ}$ \\
$3^{d}$ & $80 \%$ acetone & 25.0 & $4.6 \times 10^{9}$ & $4.6 \times 10^{\circ}$ \\
$4^{d}$ & $70 \%$ dioxane & 25.0 & & $\left(3 \times 10^{8}\right)$ \\
$5^{f}$ & $97 \% \mathrm{CF}_{3} \mathrm{CH}_{2} \mathrm{OH}$ & 100.0 & $1.2 \times 10^{8}$ & $1.2 \times 10^{8}$
\end{tabular}

- Calculated from the $0 \mathrm{Ms} / \mathrm{OPNB}$ rate ratio, assuming the $\mathrm{OTs} / \mathrm{OMs}$ rate ratios (at $25^{\circ} \mathrm{C}$ ) given in ref $9 \mathrm{~b}$. ${ }^{\circ} \mathrm{Kinetic}$ data from Tables I and II. ' Kinetic data from Table III. 'Kinetic data for $p$-nitrobenzoate extrapolated from 125 and $100^{\circ} \mathrm{C}^{12}$ ) and for mesylate estimated from data in $80 \%$ ethanol/water ${ }^{6}$ by an $m Y_{0 x}$ plot. 'Kinetic data for $p$-nitrobenzoate extrapolated from 185, 170 , and $140^{\circ} \mathrm{C}$ (refs $12 \mathrm{~b}$ and $12 \mathrm{c}$ ) and for tosylate estimated from data in acetic acid (ref $12 \mathrm{~d}$ ) by an $m Y_{\text {or }}$ plot. $f$ Kinetic data from refs 6 and 120 .

Table V. Temperature Dependence of Mesylate/p-Nitrobenzoate Rate Ratiosa

\begin{tabular}{ccccc} 
& \multicolumn{4}{c}{ temp, $^{\circ} \mathrm{C}$} \\
\cline { 2 - 5 } substrate & 25 & 50 & 75 & 100 \\
\hline benzhydryl $1^{b}$ & $3.3 \times 10^{9}$ & $9.0 \times 10^{8}$ & $3.0 \times 10^{8}$ & $1.1 \times 10^{8}$ \\
1-adamantyl 2c & $2.6 \times 10^{9}$ & $6.2 \times 10^{8}$ & $1.9 \times 10^{8}$ & $6.4 \times 10^{7}$
\end{tabular}

Tables I and II. ' Kinetic data from Table III.

reported here for solvolyses of 1 and 2. Extrapolations using the Arrhenius equation amplify experimental errors, e.g., a $5 \%$ error at $140^{\circ} \mathrm{C}$ is amplified about 5 -fold at 50 ${ }^{\circ} \mathrm{C}$. Also, curvature of Arrhenius plots due to heat capacity effects $^{14}$ can lead to errors of at least $100 \%$ for extrapolations from 150 to $25^{\circ} \mathrm{C}$. The latter results are based on a trial calculation for the solvolysis of methyl benzenesulfonate in water for which the heat capacity of activation (-36 cal mol $\mathrm{mog}^{-1} \mathrm{de}^{-1}$ is relatively small. As $\Delta H^{*}$ is temperature dependent, varying in this case by $3.6 \mathrm{kcal} / \mathrm{mol}$ over a $100^{\circ} \mathrm{C}$ range, extrapolations tend to give high results regardless of whether they are from higher or from lower temperatures. For our results for solvolyses of 1 and 2 (Table IV), extrapolations have been limited to $25-35^{\circ} \mathrm{C}$ for each substrate, so errors should be small and will tend to cancel.

Because the activation energies for solvolyses of mesylates and $p$-nitrobenzoates differ by $10 \mathrm{kcal} / \mathrm{mol}$, the measured rate ratios decrease significantly as the temperature is increased (Table V). The small differences in results for solvolyses of 1 and 2 (Table V) are due, at least in part, to extrapolation errors. The rate ratio for 5 (Table IV) is as expected for a value at $100^{\circ} \mathrm{C}$, and the ratio for 3 is also in satisfactory agreement with the other results. However, the rate ratio for 4 appears to be too low, perhaps because of acyl-oxygen fission in the highly unreactive $p$-nitrobenzoate $\left(4, \mathrm{X}=\mathrm{OCOC}_{6} \mathrm{H}_{4} \mathrm{NO}_{2}\right)$. Other experimental difficulties associated with kinetic studies of unreactive 3,5-dinitrobenzoates have previously been reported. 15

Why have previous literature estimates of tosylate $/ p$ nitrobenzoate rate ratios varied so widely? Temperature effects do not account for the discrepancies. 3 Also, solvent effects on the rate ratio are expected to be small. Logarithms of rate constants for solvolyses of 1-adamantyl trifluoroacetate 2 ( $\mathrm{X}=\mathrm{OCOCF}_{3}$ ) in aqueous acetone, ethanol, and methanol and in $97 \%$ trifluoroethanol and hexafluoro-2-propanol at $25^{\circ} \mathrm{C}$ plot linearly (slope 1.04)

(14) Roberteon, R. E. Prog. Phys. Org. Chem. 1967, 4, 213.

(15) Friedrich, E. C.; Tagrart, D. B. J. Org. Chem. 1978, 43, 805. 
VB 1- and 2-adamantyl toaylates ( $\left.Y_{O N}\right)_{1}^{16}$ and $Y_{O m}$ has also been shown to be a satisfactory solvent parameter for correlating rates of solvolyses of $p$-nitrobenzoates. $30,16 b, c$

There may be differences in strain energy released on ionization of $p$-nitrobenzoates and sulfonates, similar to those noted in comparisons of tertiary chlorides and $p$ nitrobenzoates. ${ }^{\text {7b }}$ Tosylate/halide rate ratios for secondary and tertiary substrates are strongly influenced by steric factors. ${ }^{17}$ The lower estimated tosylate/ $p$-nitrobenzoate ratios (ca. 107) are based on an intermediate calculation of rate data for chlorides, ${ }^{\text {sa }}$ in which data for both secondary and tortiary substrates are included. Tosylate/ chloride rate ratios from secondary systems give ratios that are too small for direct comparisons with $p$-nitrobenzoate/chloride rate ratios from tertiary systems, and hence low tosylate / $p$-nitrobenzoate ratios were obtained. ${ }^{30}$

Trifluoroacetates would be more suitable than chlorides as "bridges" between reactive sulfonates and unreactive p-nitrobenzoates because they are similar sterically. Also, trifluoroacetates are about as reactive as chlorides, ${ }^{16}, 18$ and they can be prepared directly from alcohols without the possibility of carbocationic rearrangements. A minor disadvantage of trifluoroacetates is their low solubility. ${ }^{162186}$

A rate ratio of $490 \pm 20$ for solvolyses of tosylates in acetic acid at $25^{\circ} \mathrm{C}$ and 3,5-dinitrobenzoates in $60 \%$ acetone/water at $100^{\circ} \mathrm{C}$ has previously been established for three cyclopropylcarbinyl substrates. ${ }^{19}$ At $25^{\circ} \mathrm{C}$, 3,5-dinitrobenzoates solvolyze six times faster than $p$ nitrobenzoates, 11,20 which are 20-25 times more reactive than benzoates. ${ }^{2 c}$ Relative rates of solvolyses of sulfonate esters can be obtained from a compilation of data for tosylates and mesylates (see Table 5 of ref $9 \mathrm{~b}$ ) or from $\rho$ values for solvolyses of arenesulfonates. $2 a, 2 b$

The sulfonate/ $p$-nitrobenzoate rate ratios discussed here are ratios of "titrimetric" rate constants. Benzhydryl $p$ nitrobenzoate $\left(1, \mathrm{X}=0 \mathrm{OCOC}_{6} \mathrm{H}_{4} \mathrm{NO}_{2}\right)$ is known to undergo ${ }^{18} \mathrm{O}$ exchange about three times faster than solvolytic release of acid, ${ }^{21}$ and similar observations have been made for sulfonates. ${ }^{22}$ A note of caution ${ }^{232}$ about a previous assumption of constant tosylate/bromide rate ratios was based on $\rho^{+}$values for solvolyses of 1-aryl-1-(trifluoromethyl)ethyl substrates; $\rho^{+}$was -6.85 for tosylates ${ }^{23 b}$ and -10.3 for bromides. ${ }^{23}$ However, only one substituent (Me) was common to these two plots. Also, bromides are structurally less similar to tosylates than are $p$-nitrobenzoates.

\section{Conclusion}

Tosylate/p-nitrobenzoate solvolysis rate ratios $\left(3 \times 10^{\circ}\right.$ in $80 \%$ ethanol/water at $25^{\circ} \mathrm{C}$ ) are relatively insensitive to solvent and structural effects (steric and perhaps also electronic effects). The ratio varies almost 100 -fold over a $100^{\circ} \mathrm{C}$ range of temperatures and, allowing for this effect,

(16) (a) Bentley, T. W.; Roberte, K. J. Chem. Soc., Perkin Trans. 2 1989, 1055. (b) MeLonnan, D. J.; Martin, P. L. J. Chem. Soc., Perkin Trans. 2 1082, 1001. (c) Allon, A. D.; Kwon-Chip, J. M.; Lin, W. C.; Nzuyen, P.; Tidwoll, T. T. Can. J. Chem. 1990, 68, 1709.

(17) Fry, J. L.; Lancolot, C. J.; Lam, L. K. M.; Harrie, J. M.; Binghem, R. C.: Raber, D. J.; Hall, R. E. Schloyer, P. Y. R. J. Am. Chem. Soc. 1970, 92, 2538. Se aleo: Lome, J. S.; Luong, P. K.; Duboin, J.-E. J. Am. Chem. Soc. $1977,99,6478$.

(18) (a) Furcayiu, D.; Jthme, J.; Rachandt, C. J. Am. Chem. Soc. 1985, 107, 6717. (b) Lembert, J. B.; Choliue, E. C. J. Am. Chem. Soc. 1900, 112, 8120.

(19) Baldwin, J. E. Focleonon, W. D. J. Am. Chem. Soc. 1988, 90, 4303. 2321.

(21) Gooring, H. L.; Hopf, H. J. Am. Chem. Soc. 1971, 93, 1224

(22) (a) Puradivi, C.; Bunnott, J. F. J. Am. Chem. Soc. 1985, 107, 8223.

(b) Dias, A. F.; Laedine, L; Winatein, S. J. Am. Chem. Soc. 1968, 90, 1804.

(23) (a) Liu, K.-T.; Wu, Y. W. J. Chem. Res. 188, 108. (b) Llu, K.-T.;

Kuo, M.-Y.; Shu, C.-F. J. Am. Chem. Soc. 1982, 104, 211. consistent results (Table IV) have been obtained for four substrates (1-3 and 5). Previous estimates of tosylate/pnitrobenzoate rate ratios (spanning nearly 3 orders of magnitude at $25^{\circ} \mathrm{C}$ ) are unreliable because of the indirect comparisons required. The corresponding tosylate/3,5dinitrobenzoate rate ratio is $5 \times 10^{8}$ at $25^{\circ} \mathrm{C}$.

\section{Experimental Section}

Chemicals. 1-Adamantyl p-nitrobenzoate (2, X = $\mathrm{OCOC}_{6} \mathrm{H}_{4} \mathrm{NO}_{2}$ ) was recrystallized from ethanol, mp $188-189^{\circ} \mathrm{C}$ (lit. ${ }^{24} \mathrm{mp} 185.8-186.1^{\circ} \mathrm{C}$, 1-adamantyl mesylate $(2, \mathrm{X}=0 \mathrm{Mo})$ was prepared as described previously, ${ }^{\text {coses }}$ benahydryl $p$-nitrobenzoate $\left(1, \mathrm{X}=\mathrm{OCOC}_{3} \mathrm{H}_{4} \mathrm{NO}_{2}\right)$ was recrystallized from $50 / 50$ hexane/acetone, mp 134-135.5 ${ }^{\circ} \mathrm{C}$ (lit. $.^{\circ 3} \mathrm{mp} 131-133^{\circ} \mathrm{C}$ ), and benzhydryl mesylate $(1, X=0 \mathrm{Ms})$ was prepared in situ.

Kinetics. Conductimetric procedures for fast reactions were

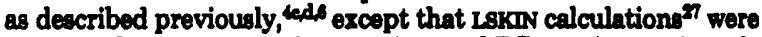
performed in a few seconds on an Amstrad PC1512 (approximately equivalent to an IBM XT). Because 1-adamantyl p-nitrobenzoate is relatively insoluble, the following procedure was adopted: the substrate $(7.5 \mathrm{mg})^{23}$ was mired with dry acotonitrilo (1 mL), warmed, sonicated for $10 \mathrm{~min}$, and then filtered. 2,6-Dimethylpyridine $(1 \mu \mathrm{L})$ was added to the solvolysin medium ( 50 $\mathrm{mL})$, this solution $\left(1.7 \times 10^{-4} \mathrm{M}\right)$ was dispensed into 5 -mL ampules, and the acetonitrile solution $(25.0 \mu \mathrm{L})$ was then added $\left(<10^{-}\right.$ M p-nitrobenzoate). HPLC analyses required only $25.0 \mu \mathrm{L}$ of solution, eluted with $95 \%$ methanol/water, with detection at 260 $\mathrm{nm}(A=0.05)$.

Acknowledgment. We are grateful to the SERC (UK) for a studentship (S.J.N.) and for two HPLC equipment grants, to the British Council for support via the AngloGerman Academic Research Collaboration, and to M. S. Garley for further modifications to the LSKNN computer program allowing convenient operation on a PC.

Registry No. $1(X=0 M 8), 135513-20-1 ; 1$ (X $=$ $\left.0 C O C_{6} \mathrm{H}_{4}-p-\mathrm{NO}_{2}\right), 25115-94-0 ; 2(\mathrm{X}=0 \mathrm{MB}), 25236-60-6 ; 2(\mathrm{X}=$ $\left.\mathrm{OCOC}_{6} \mathrm{H}_{6}-\mathrm{p}-\mathrm{NO}_{2}\right), 968-84-3$.

(24) Schleyer, P. v. R.; Nicholas, R. D. J. Am. Chem. Soc. 1811, 88, 182 (25) Crossland, R. K.; Servis, K. L. J. Org. Chem. 1970, $36,3185$. (26) Silver, M. S. J. Am. Chem. Soc. 1861, 83, 404.

(27) DeTar, D. F. In Computer Programs in Chemiatry; Vol. 1, DeTar, D. F., Ed.; W. A. Benjemin: New York, 1968; vol. 1, pp 126-178.

(28) Four-fold lees sample could conveniently have used if the semple had been leses plentiful.

\section{Acyclic 1,4-Radical Cations. Direct Observation and Stability}

Sachiko Tojo, Susumu Toki, ${ }^{\dagger}$ and Setsuo Takamuku*

The Institute of Scientific and Industrial Research, Osaka University, Ibaraki, Osaka 567, Japan

Received October 19, 1990 (Revised Manuscript Received July 1, 1991)

\section{Introduction}

One of the most characteristic reactions of radical ions is the unimolecular or biomolecular formation of "distonic radical ion" in which charge and radical sites are separated from each other. ${ }^{1}$ An introduction of an electron-donating group such as a methoxyl group which stabilizes the cationic site of the distonic radical ion enhances the efficiency and the selectivity of the reaction of radical cations. ${ }^{2} \mathbf{A}$ typical example of the distonic radical ions is an acyclic

- To whom correspondence should be addreseed.

Present addreas: Nara National Colloge of Technolory, 22 Yatacho, Yamatokoriyama, Nara 639-11, Japan. 